\title{
Classic Reading and Experience of Chinese Language and Literature in Computer Network Environment
}

\author{
Qingyun Chen ${ }^{1}$
}

\author{
${ }^{1}$ Fuzhou Preschool Education College, Jiangxi, Fuzhou,344000 \\ 739960103@qq.com
}

\begin{abstract}
With the rapid development of network technology, electronic reading has become the main way for modern people to read. Electronic reading is also imperceptibly entering people's lives, affecting all aspects of people's lives and work. With the development of computer network information technology, information sharing has become a hot topic. This paper summarizes the major of Chinese language and literature, and analyzes the related manifestations of classical reading and experience of Chinese language and literature under the computer network environment. Moreover, this paper analyzes the problems and solutions of classical reading and experience of Chinese language and literature in computer network environment.
\end{abstract}

Keywords: Computer Network, Chinese Language and Literature, Reading Experience

\section{INTRODUCTION}

In the environment of computer network, more and more people surf the Internet, so to a certain extent, the number and level of reading of Internet users have been improved. Many fragmented reading information make Internet users read faster and more convenient, to a certain extent enhance the people's reading experience and interest. However, the classical works of Chinese language and literature are a kind of precipitation of accumulated history of years, which contains profound philosophy and connotation. In the face of the impact of online fast food culture, the classical reading and experience of Chinese language and literature in China have also been challenged.

\section{OVERVIEW OF THE CHINESE LANGUAGE AND LITERATURE}

The major of Chinese language and literature is one of the most established and oldest majors in Chinese colleges and universities, but the major of Chinese language and literature is facing many difficulties in ethnic colleges and universities.

Among many colleges and universities with Chinese language and literature major, ethnic colleges and universities are in a special position. National colleges and universities are specialized in training minority cadres and professional and technical personnel in China.
At present, there are 13 undergraduate colleges and universities in China, of which 6 are directly affiliated to the State Civil Affairs Commission, namely, the Central University for nationalities, the Southwest University for nationalities, the Central South University for nationalities, the Northwest University for nationalities, the Northwest Second Institute for nationalities and the Dalian Institute for nationalities. In addition, there are some comprehensive colleges and universities in minority areas, such as Xinjiang University, Inner Mongolia University, Tibet University, Guangxi University, Ningxia University, Qinghai normal University, etc., which have Chinese language and literature majors. The early setup was in the 1950s, such as Southwest University for nationalities in 1956,1957 undergraduate. The following is the top 10 ranking of Chinese language and literature in colleges and universities in China.

Table 1. Top 10 Chinese Language and Literature Rankings in Chinese Universities.

\begin{tabular}{|l|l|l|}
\hline ranking & school name & rank \\
\hline 1 & Beijing Normal University & $\mathrm{A}+$ \\
\hline 2 & Peking University & $\mathrm{A}+$ \\
\hline 3 & Sichuan University & $\mathrm{A}+$ \\
\hline
\end{tabular}




\begin{tabular}{|l|l|l|}
\hline 4 & Fudan University & $\mathrm{A}+$ \\
\hline 5 & Shandong University & $\mathrm{A}+$ \\
\hline 6 & Nanjin university & $\mathrm{A}+$ \\
\hline 7 & Zhongshan University & $\mathrm{A}+$ \\
\hline 8 & Huazhong Normal University & $\mathrm{A}+$ \\
\hline 9 & Fujian Normal University & $\mathrm{A}+$ \\
\hline 10 & Shanghai Normal University & $\mathrm{A}+$ \\
\hline
\end{tabular}

Compared with the construction of Chinese language and literature majors in all kinds of comprehensive universities and normal colleges, the Chinese language and literature majors in ethnic colleges have similar problems in teaching staff, professional construction, teaching reform, talent training and so on. First of all, the Chinese language and literature majors in ethnic colleges cannot be compared with comprehensive universities in many aspects; secondly, the emphasis on highlighting national characteristics in our ethnic colleges and universities is not enough, neither funds nor scientific research projects can be inclined to them; thirdly, comrades of other majors in ethnic colleges and universities do not realize the basic, applied status and application of Chinese language and literature majors, blindly emphasizing the practicability and practicability of their respective majors, ignoring the supporting role of Chinese language and literature to other applied and practical majors[1].

First of all, Chinese is a necessary tool for students in ethnic colleges and universities. No matter what major students choose in the school, they cannot do without the crutch of Chinese. If the foundation of Chinese is poor, learning all kinds of professional knowledge will inevitably face many difficulties, which will certainly affect their professional study and research. Secondly, Chinese language can improve the competitiveness of students in ethnic colleges and universities. Nowadays, the demand for the comprehensive quality of talents is getting higher and higher. If the students are only proficient in a certain national language and lack the ability to express and write Chinese, the students will feel more and more employment pressure than others when they graduate. Third, Chinese language plays an increasingly important role in the common exchange and economic construction of all nationalities in the Chinese family. There are 55 ethnic minorities in the Chinese family. The Party and the government have always advocated "respecting the language and characters of ethnic minorities ", and the Constitution clearly stipulates that" all ethnic groups have the freedom to use and develop their own language and characters ". National language is necessary for education and cultural inheritance in ethnic areas. However, Chinese is the most extensive communication tool in China and one of the working languages of the United Nations. Therefore, the cultivation of minority talents cannot be separated from the study of Chinese language and philology. Some minority scholars have long pointed out :" the more ethnic minorities know Chinese, the stronger the ability to use Chinese, the faster the political, economic and cultural development of the nation[2].

Therefore, the study of Chinese language and literature by minority students can further enhance the understanding of national unity, establish the ideology that Han nationality cannot be separated from ethnic minorities and ethnic minorities in the Chinese family, and establish the consciousness of "pluralistic and integrated pattern of the Chinese nation ", so as to strengthen the cohesion of the Chinese nation.

\section{RELATED EXPRESSIONS OF CLASSICAL READING AND EXPERIENCE OF CHINESE LANGUAGE AND LITERATURE IN COMPUTER NETWORK ENVIRONMENT}

An excellent work can open people's hearts, whether it is its words or symbols, or its language expression, can give people infinite strength and spiritual comfort, often in the silent text contains extremely profound connotation and philosophy. In the environment of computer network, people's traditional reading methods have also changed. In this era, people can choose the types and ways of reading books actively. Because of the huge storage space of computer network information technology, people can break through the limitation of time and space while reading. In this environment, it has a great influence on changing the way people read and practice, but the application of computer network information technology in Chinese language and literature has both positive and negative sides. In the computer network environment, a large number of people love Chinese language and literature, but in the computer network environment, few readers want to find Chinese language and literature. Under the computer network environment, the classical reading and experience of Chinese language and literature are mainly manifested in the following two aspects.

\subsection{Superiority}

Because the computer network has certain convenience, sharing, economy and virtuality, people can save money and time in a certain sense in reading, and the electronic version of Chinese language and literature reading breaks the boundary between time and space. At the same time, because of the sharing of computer 
network, it can make the public read Chinese language and literature widely, which is beneficial to the output and promotion of Chinese language and literature, and can also provide individual reading experience. Help readers find reading interest and direction quickly, and optimize readers' reading structure. In addition, electronic reading is more affordable than paper reading. It only needs to read and experience all kinds of classical works of Chinese language and literature through electronic readers. Under the influence of Chinese language and literature, it can purify the network atmosphere and create a harmonious and healthy network environment[3].

\subsection{Insufficient}

Nowadays, because of the openness of computer network environment, all kinds of online novels and online games occupy the screen of the public. But this deviates from the main intention of Chinese classical works and does not accord with the single emotional experience of Chinese language and literature. In addition, the modern network environment is extremely complex, management is very difficult, it is difficult to guide people to correctly read and experience Chinese language and literature, cannot understand and understand the profound philosophy and connotation of Chinese language and literature. In the large environment of computer network environment, many fragmented, non-nutritional reading can bring some pleasure to people in a short time, people often prefer this fragmented way of reading, but this way of reading although the amount of information received is huge, but it is difficult to bring people deep thinking, no educational significance. Although the current network market will package many Chinese language and literature works and appear in the form of video in the public view, this way of promoting Chinese language and literature through marketing has also lost the essential connotation of Chinese language and literature. Its core value is difficult to show. Therefore, this is the computer network environment Chinese language and literature classic reading and experience disadvantage.

\section{PROBLEMS OF CLASSICAL READING AND EXPERIENCE OF CHINESE LANGUAGE AND LITERATURE IN COMPUTER NETWORK ENVIRONMENT}

\subsection{Changing Reading Style}

With the development of computer network, people's reading style has changed from the most traditional paper reading to shared electronic reading. In addition, many classical Chinese language and literature began to show in various forms. Compared with the traditional reading style, it is difficult for readers to understand the original literary connotation thoroughly under the change of network technology. Therefore, the classical reading style of Chinese language and literature has changed in the computer network environment, which will affect the display of the connotation of classical literature. This is also one of the problems faced by the classical reading and experience of Chinese language and literature under the computer network environment.

\subsection{Changing patterns of thinking}

With the development of society, people's reading thinking of classical works has also changed greatly. The original literary works can only be disseminated in the form of paper characters. Nowadays, many classical literary works can be displayed in different forms through computer network technology.

At the same time, under the influence of modern and complex network environment, many network words begin to emerge, which is quite different from the aesthetic in Chinese language and literature classics. All kinds of factors limit the survival and development of Chinese language and literature in the network environment, and people's thinking mode has changed. Under the environment of computer network, Chinese language and literature gradually become lively and humorous expression, which has also become the result of the change of people's thinking mode. However, in the environment of computer network, Chinese language and literature cannot exist alone without theory, which will lose its essence and connotation. As a result, the reading level of the public is difficult to improve, but also makes people lose the ability to think and read independently in the environment of computer network. Therefore, this is the current computer network environment of Chinese language and literature classic reading and experience facing the problem[4].

\section{THE SOLUTIONS OF CLASSICAL READING AND EXPERIENCE OF CHINESE LANGUAGE AND LITERATURE IN COMPUTER NETWORK ENVIRONMENT}

\subsection{Improving the Reading Environment of Chinese Language and Literature}

Nowadays, in order to get rid of the influence of computer network environment on the reading and experience of Chinese language and literature classics, we also need to improve the environment of Chinese language and literature reading. Therefore, it is necessary for all aspects to work together to guide people to actively participate in the reading of classical works of Chinese language and literature. At the same time, colleges and universities should enrich the number of Chinese language and literature classics in their libraries and facilitate students to borrow and learn. In family education, parents should lead by example to read 
classical literary works, help children develop the habit of reading, and change their way of thinking by reading classical works of Chinese language and literature with their children. Let children form a unique way of thinking and learn to think from different positions. Finally, it is necessary to mobilize the whole society to create a good reading atmosphere of Chinese language and literature classics, and always present the high quality content in front of the public. At the same time, we also need to open the city reading hall to add more Chinese language and literature classics for everyone to read. Therefore, improving the reading environment of Chinese language and literature is an important way to solve the problem of classical reading and experience of Chinese language and literature in the current computer network environment.

\subsection{To change the expression of Chinese language and literature classics}

The reading of Chinese language and literature classics in the environment of computer network has some advantages, such as information sharing, sufficient resources, no time limit, low cost and so on. But taking into account these advantages, we need to prevent many filthy words from flowing into the public's sight and polluting the network environment because of the openness of the network environment[5].

Therefore, it is necessary to regulate the advantages of reading classical works of Chinese language and literature in computer network, correctly use network information technology, deeply explore the classical works of Chinese language and literature, and display the unique connotation and values of classical works of Chinese language and literature in different forms. For example, through the use of network technology audio, video, image and other technologies, the Chinese language and literature more thoroughly in front of the public. In order to guide people to think deeply about the classical works of Chinese language and literature from different angles, in addition, it can also enhance the interest of a large number of netizens in reading Chinese language and literature. To some extent, it can improve the public's experience of reading Chinese language and literature.

Nowadays, in the computer network environment, many classical books of Chinese language and literature have set up seminars and knowledge lectures to advocate people to actively express their feelings and opinions after reading classical works of Chinese language and literature. At the same time, it also makes the classical works of Chinese language and literature more popular. Therefore, in the environment of computer network, the expression of classical works of Chinese language and literature has changed to a certain extent. It is no longer a simple use of words to express the profound connotation and philosophy of its works. It can be expressed in various forms such as pictures, video and audio in computer networks. At the same time, it can also increase readers' interest in reading classical works of Chinese language and literature. Therefore, changing the expression of Chinese language and literature classics is the main way to solve the problem of Chinese language and literature classics reading experience under the computer network environment[6].

\section{CONCLUSION}

In a word, under the environment of computer network, it has some advantages for the reading and experience of classical works of Chinese language and literature, which can make more people come into contact with classical works of Chinese language and literature, and better spread and carry forward them. However, at the same time, it also brings many problems. People's reading style and thinking mode have changed greatly, which is nothing more than a challenge to the reading of Chinese language and literature classics. We need to overcome the disadvantages of this environment and carry forward its advantages.

\section{REFERENCES}

[1] Yin,S.M.(2019)Reading and Experience of Chinese Language and Literature Classics in Network Age.Chinese newspaper.93-94.

[2] Xu,J.L.(2018)Classic Reading and Experience of Chinese Language and Literature in the Network Age.Theatre House.248.

[3] Zhou,J.Y.(2019)Classic Reading and Experience of Chinese Language and Literature in the Network Age.China National Expo.113-114.

[4] Wu,X.M.(2020)Reading and Experience of Chinese Language and Literature Classics in Network Age.International Public Relations.

[5] Zhao,X.(2020)Study on Reading and Experience of Chinese Language and Literature Classics in Network Age.Journal of Taiyuan City Vocational and Technical College.141-143.

[6] Xu,Q.M.(2017)Classical Reading and Experience Analysis of Chinese Language and Literature in Network Age.Literature Education (Part II).117. 